\title{
Avaliação de programas, indicadores e projetos em educação infantil
}

\section{Fúlvia Rosemberg}

Fundação Carlos Chagas e PUC/SP

\section{Introdução}

A educação infantil, um novo campo de prática social - que consiste em educar e cuidar de crianças de até 6 anos em instituições coletivas - apóia-se em três tipos de fundamentos (Spodek, 1982): na intuição, em valores e no conhecimento científico.

A intuição vem informando uma série de decisões no campo da educação infantil, estejam elas situadas no plano micro (por exemplo, ações envolvendo educadoras e crianças), ou no plano macro (por exemplo, delimitação de metas de cobertura). Este fundamento - que vem da própria prática sistematizada - constitui uma das principais bases para a ação em educação infantil brasileira, haja visto o número de pessoas que atuam no campo e que não usufruíram de uma formação profissional específica inicial ou continuada. Aqui refiro-me tanto ao(à) professor(a) de educação infantil, quanto ao(à) técnico(a), administrador(a), sindicalista, político(a) e, até mesmo, ao(à) assessor(a).

Se a intuição constitui uma base importante para fundamentar a ação, ela é insuficiente, pois nem sempre é generalizável ou passível de exame crítico (Spodek,
1982). Ser generalizável e passível de crítica, de confronto com análise oferecida por outros interlocutores, são qualidades necessárias pois estamos falando de educação infantil em espaços coletivos, para além da esfera privada, portanto, públicos.

Outro fundamento essencial para a ação no campo da educação infantil são os valores individuais e sociais, o que se considera que sejam necessidades e experiências válidas e adequadas para crianças e adultos. Qualquer proposta de educação, de socialização, de cuidado se orienta por parâmetros do que seja bom, desejável em oposição ao que é tido como indesejável, ruim. Observa-se uma grande variação social e histórica quanto aos valores que devem reger a educação em qualquer etapa da vida. Esta variação é tanto mais intensa quanto menor a criança, pois, nas sociedades contemporâneas, a criança pequena é considerada um ser imensamente plástico.

Certos valores são consensuados socialmente, originando diretrizes para a ação que são, elas mesmas, produto de negociação, convencimento ou imposição. Em sociedades livres, ou que buscam como meta a diversidade e liberdade de expressão, admite-se que existam 
diferenças genuínas de valores, gostos e de sentimentos. “Os princípios normativos e morais não podem, por definição, ser todos e sempre abrangidos por consenso: determinar que a pessoa deve fazer isso ou aquilo é admitir que algumas pessoas, pelo menos, não saberão reconhecer livremente a necessidade absoluta de não agir de outra maneira" (Ziman, 1979). Isto nos coloca ante algumas questões inquietantes. Quais os limites de atuação para transformar, alterar os valores de uma pessoa, de um grupo, de uma instituição, de uma nação? Quem dispõe do melhor código de valores? Quais os mais justos, corretos e válidos? Ao olhar de quem? Dos profissionais que trabalham no estabelecimento? Dos pais e das mães? Das crianças? Do governo? Das organizações multilaterais?

No campo da educação infantil, especialmente de políticas, programas e projetos destinados à criança pequena pobre, destaco pontos inquietantes no plano dos valores.

a) Nota-se uma tendência a que modelos hegemônicos a baixo custo sejam implantados nos países em desenvolvimento, reduzindo as alternativas de opção familiar. Ora, a literatura (Bloch \& Buisson, 1998) mostra que a demanda por educação infantil e o tipo de programa preferido/ escolhido estão também orientados por valores, sobre o que significa ser uma boa mãe/um bom pai e um bom espaço educacional para a criança. Modelos hegemônicos reduzem as possibilidades de escolha das famílias, não dando vazão à expressão de seus valores. De que instrumentos dispomos para apreender a demanda das famílias por tipo de serviço de educação infantil?

b) Vários programas contemporâneos destinam-se à educação de pais - isto é, mães pobres para que eduquem e socializem seus filhos pequenos de acordo com as novas necessidades do mundo globalizado, esquecendo-se que nesta engenharia social está-se atuando também no plano de valores que foram constituídos durante inúmeras gerações. Como avaliar impactos no plano da alteração de valores?

c) Nós adultos instruídos consideramos que sabemos não apenas o que é bom para os pobres, mas que agimos sempre em nome das crianças, ou do "maior interesse da criança", o que, muitas vezes, resta provar. Quais as estratégias disponíveis para dar voz à criança pequena usuária de serviço de educação infantil? E para aquelas que ainda não dispõem de voz?

\section{O conhecimento científico e as políticas de educação infantil}

O terceiro fundamento da prática no campo da educação infantil é o conhecimento que decorre de pesquisas e teorias científicas formuladas no próprio campo da educação infantil ou em disciplinas correlatas: da Saúde à Psicologia, passando pela Educação, Antropologia, História, Sociologia e, nas últimas décadas, centrandose cada vez mais na Economia.

O que distingue o conhecimento científico dos demais fundamentos da educação infantil? Com certeza não significa que tal fundamento seja neutro, apolítico ou que não se apóie na intuição. Considero que o que distingue o conhecimento científico é que, além de ultrapassar o aqui e agora do contexto de sua produção (mesmo guardando os atributos de ser sempre histórico), ele oferece uma interpretação da realidade que não é imposta mas que pode ser provada. "Provar é apresentar razões, fundamentações, evidências, elucidação; impor é afirmar ou aceitar, silenciar os questionamentos ou discordâncias. Provar é tratar o outro como pessoa capaz de ser convencido; impor é tratar o outro como uma pessoa que deve ser submetida" (Thompson, 1995, p. 411).

Neste sentido, o conhecimento científico é público e os argumentos em que baseia suas interpretações devem passar pelo confronto da crítica dos pares. Assim, sustento que um indicador de uma saudável comunidade científica é a disponibilidade para a competição entre diversas perspectivas, o confronto público, o pluralismo. “É provável que, ao contrário de um processo de concentração, tais condições de pluralismo serão adequadas para que a pesquisa desempenhe seu papel de acelerar o processo de aprendizagem na área de elaboração de políticas" (Lauglo, 1997, p. 29). Advogo que o conhecimento científico quando assim conceituado consti- 
tui um instrumento auxiliar na formulação e avaliação de políticas sociais. Explicitarei, a seguir, seus limites e possibilidades. Para tanto, é necessário conceituar o que sejam políticas sociais.

A literatura crítica contemporânea, apesar de apontar a ausência de definições stricto sensu de política social, tende a caracterizá-la como intervenção do poder público no sentido de ordenamento hierárquico de opções entre necessidades e interesses explicitados pelos diferentes segmentos que compõem a sociedade. Assim, por exemplo, Santos (1987) fala em ordenamento "de escolhas trágicas segundo um princípio de justiça coerente e consistente”; Oszlak e O’Donnell (1976) se referem a “... um conjunto de ações e omissões que manifestam uma determinada modalidade de intervenção do Estado em relação a uma questão que concita a atenção, o interesse, a mobilização de outros atores na sociedade civil".

Quando apontamos para a atuação do Estado no sentido do ordenamento de interesses e de necessidades, estamos simultaneamente aceitando que os interesses e necessidades que orientam as opções do Estado sejam expressos pelos vários atores que compõem o todo social e que as respostas do Estado “... emergem [...] de um processo de escolhas sucessivas, que envolve confrontos, atritos, coalizações, pressões e contrapressões: que nesse processo de escolha, são muitas as forças envolvidas - os segmentos sociais, os estamentos técnicoburocráticos do Estado, o congresso, a presidência, os partidos, os sindicatos, os movimentos sociais, os especialistas e, não raro, suas corporações. É esse processo que define, em cada momento, como será a política social, que prioridade elegerá [...]" (Abranches, 1987, p. 11).

Neste entrejogo de conflitos, tensões, coalizões e negociações participam também cientistas, suas corporações e o conhecimento produzido por cientistas, disponível no acervo social ou especialmente elaborado para um programa/projeto específico. "Sob condições favoráveis, a pesquisa social pode trazer muitas contribuições importantes para a formulação de políticas: pode colocar em evidência problemas que têm sido ignorados, ajudar a diagnosticar problemas sociais, colocar novas questões, colocar os temas em perspectiva mais ampla" (Lauglo, 1997, p. 28). Assim, ao lado dos demais atores sociais, também, participam desta barganha pesquisadores e o produto de seu trabalho. Produto de seu trabalho que tanto pode ser produção científica, como foi aqui conceituada, e informar, então, os demais atores sociais (inclusive crianças, pais/mães e profissionais de educação infantil) que participam destas negociações; ou produto do trabalho que, não obstante o rótulo de conhecimento científico, constitui uma interpretação não provada, que apenas legitima opções políticas previamente assumidas e, portanto, não informa os diferentes atores sociais.

Ou seja, quando defendo que o conhecimento científico deve constituir um dos fundamentos das negociações em políticas sociais, não estou assumindo que é o conhecimento quem deva determinar, diretamente, as prioridades em políticas públicas. Nesta determinação, o conhecimento deve instrumentar os atores, pois estas opções são políticas, resultantes do jogo de interesses e pressões. Esta ressalva me parece importante, pois observou-se e observa-se onipotência e manipulação cientificista, pretendendo-se que o conhecimento acadêmico, em si, carregado da aura da neutralidade científica, seja inquestionável e possa orientar opções corretas, absolutas e universais de prioridades e estratégias em políticas públicas. Desta ótica, decisões políticas são travestidas do qualificativo de "decisão técnica" competente, diminuindo, portanto, o poder de barganha dos demais atores sociais.

No atual cenário mundial, a participação de especialistas e suas pesquisas no estabelecimento de prioridades, estratégias e avaliações em políticas educacionais vem sendo potencializada pela importância crescente do Banco Mundial na área (Coraggio, 1996; Rosemberg, 2000), inclusive no campo da educação infantil a partir dos anos 90 (Torres, 1996).

Com efeito, Guiachoua e Goussault (1993) assinalam que, a partir dos anos 70, o campo das pesquisas sobre desenvolvimento social foi sendo ocupado gradativamente pelas agências multilaterais, especialmente pelo Banco Mundial. Para estes autores, tal mudança tem implicações importantes: são estas instituições que asseguram a coleta, definição e análise de informações estatísticas, ou seus instrumentos; foram elas que intro- 
duziram uma preponderância anglo-saxônia sem contrapartida; elas dispõem, também, de orçamento e meios para a realização de pesquisas e estudos desproporcionais quando comparados aos de instituições nacionais; economistas e estatísticos especialistas em análise microeconômica, que privilegiam o empírico e que são competentes no estabelecimento de modelos (cenários, previsões) ganham, nestas instituições e nos governos nacionais, posição de destaque, tornando-se difícil um diálogo insterdisciplinar. Constitui-se, assim, o que Haas (apud Melo \& Costa, 1996) denomina de comunidade epistêmica, que tem como principal fonte de poder a autoridade técnico-científica amparando modelos de políticas. O grupo dominante possui as informações consideradas pertinentes, o poder de financiamento e os meios para influenciar certas categorias de atores sociais. Dispõe de canais importantes para construir o senso comum e o repertório de argumentos para apoiar decisões políticas. Análises provisórias e questionáveis podem assumir o estatuto de verdade científica apoiando, diretamente, a tomada de decisões políticas.

Isto vem ocorrendo no campo das políticas de educação infantil nos países em desenvolvimento com o tema do impacto positivo de programas a baixo custo. Por exemplo, o documento Improving the quality of primary education in Latin America and the Caribbean (Wolff et al. 1994) destaca, entre suas conclusões:

Os custos da educação formal pré-escolar são similares aos custos da educação primária e podem ser maiores se alimentação e saúde forem incluídos. [...] Programas não formais utilizando mães, supervisores profissionais e domicílios particulares são muito mais baratos que programas formais. Com boa supervisão estes programas podem ter uma qualidade adequada (p. 49). [Mais adiante, o texto conclui]: Os países da América Latina e Caribe devem inspirar-se nas experiências bem sucedidas de programas eficientes no plano dos custos, dois dos quais são o colombiano "lares vicinais" e o mexicano de treinamento de pais nos domicílios (Wolff et al., 1994, p. 54)

Ora, as aparentes evidências científicas - de que sabemos quanto custam programas não formais, que os impactos positivos de programas não formais são certezas estabelecidas, que programas não formais para edu- car as mães têm impacto positivo - parecem carecer de suporte científico. Com efeito, em seminário organizado pelo Banco Mundial (para permanecer com a mesma fonte), e que acolheu pesquisadores universitários, trabalhando em outras instituições, encontramos referências que contradizem tais "evidências". Por exemplo, Steven Barnett (1994, p. 311), da State University de New Jersey (EUA), assim se refere a custos e impacto.

Deve-se ter precaução quando se comparam programas de educação infantil formais e informais baseando-se em estimativas de custo apresentadas anteriormente [...] revisões anteriores sobre estimativas de custo de programas de intervenção destinados a crianças pequenas indicam que os custos são subestimados [...] e estudos recentes, citados por Lira (1994), sugerem que a substimação pode ser bastante séria [...]. Alguns custos podem ser de fato omitidos e o número de crianças atendidas superestimado, possivelmente um problema habitual em programas informais que não estão sujeitos a procedimentos de auditoria e acompanhamento (accountability) [...] Apesar de despender mais que o esperado, programas não formais são mais baratos que os formais. Infelizmente, as comparações entre os benefícios oriundos de programas com custo alto, médio e pequeno não são conclusivas [...] O maior problema para a validade destes estudos que comparam programas com alto e baixo custo decorre, provavelmente, do viés da seleção [dos sujeitos]... o fato de participar de dado programa de educação infantil pode ser determinado por características da família que também influenciam o crescimento e desenvolvimento da criança. (Barnett, 1997, p. 311-312)

\section{Reconceituando avaliação em educação infantil}

É necessário, pois, atentar que na construção da agenda de prioridades em políticas sociais, os atores sociais não dispõem de mesmo poder de negociação. Isto é particularmente notável no caso da educação infantil especialmente nos países em desenvolvimento - campo social que visa à produção da vida, e não à produção e administração de riquezas, objetivo menos valorizado nas sociedades contemporâneas (Izquierdo, 1994).

Com efeito, de um lado a educação infantil responde particularmente a necessidades de mulheres e crianças, segmentos sociais que tendem a ocupar a posição mais 
próxima do polo da subordinação no eixo do acesso ao poder. Em segundo lugar, nos países em desenvolvimento, políticas, programas e projetos governamentais visam à educação infantil de populações pobres, segmentos sociais que também ocupam a posição mais próxima do polo da subordinação no eixo da distribuição do poder.

E em terceiro lugar, porque nos referimos à avaliação de políticas, programas e projetos contemporâneos, isto é, que se desenvolvem na atual conjuntura mundial globalizada, em que os países do sul enfrentam os desafios das políticas de ajuste conseqüentes ao novo ordenamento econômico mundial. Redução dos gastos sociais, flexibilização dos contratos de trabalho, enfraquecimento dos espaços tradicionais de debate político (e sua substituição pelos meios de comunicação de massa) limitam o poder de participação e negociação já limitado desses atores sociais (Arriagada, 1999).

Diante deste contexto, advogo uma ampliação do conceito tradicional de avaliação de políticas, programas e projetos de educação infantil. A avaliação constitui uma forma particular de pesquisa social que tem por finalidade determinar não apenas se os objetivos propostos foram atingidos (conceituação tradicional), mas também se os objetivos propostos respondem às necessidades dos participantes diretamente concernidos pela educação infantil: pais (especialmente as mães), profissionais e crianças.

Ao recomendar esta conceituação de avaliação estou sugerindo, inicialmente, um questionamento dos objetivos que vêm orientando propostas de projetos e programas de educação infantil. Qual o seu objetivo? Os objetivos que propõem respondem a que tipos de necessidades/interesses? Os atores sociais mais particularmente interessados - pais/mães, profissionais e crianças concordam com tais objetivos? Esta pergunta é chave para orientar a montagem de pesquisas visando a avaliação de programas e projetos, pois inclui reflexão e análise relativas ao ponto de partida: os objetivos de políticas, programas e projetos.

\section{Modelosdeavaliação em educação infantil}

Uma análise da literatura internacional evidencia, de imediato, duas grandes tendências contemporâneas quanto aos objetivos da educação infantil: uma para os países desenvolvidos; outra para os em desenvolvimento. Para os países em desenvolvimento, particularmente para a América Latina dos anos 90, o principal objetivo que vem sendo proposto à educação infantil é o da prevenção do impacto da desigualdade econômica (mortalidade, desnutrição infantil), especialmente prevenção do fracasso escolar no ensino fundamental, uma estratégia para o aumento de sua eficiência.

Observo uma espécie de deslizamento do uso das pesquisas sobre impacto da educação infantil no ensino fundamental. Se de início foram efetuadas para avaliar programas em andamento (como os norte-americanos Head Start e High Scope) e seus resultados funcionaram como argumento para ampliar as fontes de recurso (vale a pena investir em educação infantil), atualmente a avaliação de impacto tem sido usada para delimitar objetivos e estratégias: melhorar os indicadores do ensino fundamental e reduzir ao mínimo os custos de programas e projetos.

Dentro desta ótica, o design dos projetos de diagnóstico/avaliação são orientados para avaliar cobertura, custo e impacto, este último geralmente medidos através de aferição do estado nutricional, da inteligência, de habilidades cognitivas, mas, raramente, do desenvolvimento social (Myers, 1992). O indicador chave deste modelo é a avaliação custo-benefício, incluindo nos benefícios principalmente as taxas de retorno. Este é o modelo particularmente presente nos estudos realizados, encomendados ou publicados pelo Banco Mundial (Coraggio, 1996; Lauglo, 1997).

Quais os problemas que detecto neste modelo? $\mathrm{Na}$ produção acadêmica latino-americana encontro em Coraggio (1996), pesquisador argentino, a crítica mais contundente ao que denomina de "viés economicista".

Para enquadrar a realidade educativa em seu modelo econômico e poder aplicar-lhe seus teoremas gerais, o Banco Mundial estabeleceu uma correlação (mais do que uma analogia) entre sistema educativo e sistema de mercado, entre escola e empresa, entre pais e consumidores de serviços, entre relações pedagógicas e relações de consumo - produto, entre aprendizagem e produto, esquecendo aspectos essenciais próprios da realidade educativa [...] O problema que, mais cedo 
ou mais tarde, os intelectuais e técnicos do Banco deverão assumir, e que agora nossas sociedades enfrentam perante as novas políticas educativas, é que nossa realidade histórica [...] não se ajusta ao modelo, e que aceitar as propostas sem discuti-las pode significar a aceitação de uma intervenção política externa, ou a introjeção de valores não propostos abertamente à sociedade como uma opção. (Coraggio, 1996, p. 102-103)

Nos países desenvolvidos, especialmente na Comunidade Européia, pode-se encontrar outro modelo de avaliação de políticas de educação infantil, que pode nos inspirar nos planos teórico-conceitual e na construção de indicadores. Refiro-me ao modelo apresentado no documento Monitoring childcare services for young people (European Comission Network on Childcare, 1994).

O documento retoma o duplo pertencimento dos serviços de educação infantil: tais serviços referem-se a políticas para infância e a políticas para igualdade de oportunidades entre homens e mulheres. Este duplo objetivo da educação infantil tem marcado a história de sua reivindicação também no Brasil (Campos, 1997; Rosemberg, 1989). Ter-se clareza do duplo objetivo deste setor da política social permite que se definam, também claramente, quais os indicadores a serem selecionados.

O modelo da Comunidade Européia pode ser resumido numa matriz de dupla entrada que atenta simultaneamente para os participantes diretamente envolvidos em programas e projetos de educação infantil - pais/ mães, profissionais/trabalhadores(as) e crianças - e para as categorias de informação: necessidades, demanda e provimento. Necessidades, demanda e provimento são expressas diferentemente conforme se considerem pais/ mães, profissionais e crianças.

O modelo conceitua necessidade como "direito socialmente reconhecido", reconhecimento que pode ser legal ou, apenas, instituído na prática. No Brasil, por exemplo, desde a Constituição de 1988, o acesso a creches e pré-escolas é tanto um direito de pais e mães trabalhadores(as) quanto das crianças de até 6 anos de idade.

Necessidades de pais/mães, crianças e profissionais não são obrigatoriamente as mesmas. Pais e mães podem ter necessidade de serviços de educação infantil para prover a guarda dos(as) filhos(as) enquanto trabalham ou para complementar a educação/socialização doméstica (o que o referido documento traduz, nas línguas latinas, por acolhimento). Estas necessidades se traduzem nos projetos de avaliação em indicadores diversos: quando se trata de avaliar o quanto a necessidade de guarda está sendo respondida por projetos e programas, tem-se que considerar, obrigatoriamente, o horário de funcionamento previsto pelo projeto. Saber se o horário de funcionamento cobre a jornada de trabalho dos pais, especialmente a das mães, passa a ser uma questão chave para avaliação do projeto/programa.

As crianças têm sempre necessidade de acolhimento (cuidado, educação), independentemente das necessidades parentais. Mesmo que da ótica dos pais/mães, a necessidade prioritária seja a de guarda, da ótica da criança ela será sempre a de acolhimento. Avaliar se os programas respondem às necessidades das crianças implica tanto em aferir o número de crianças que são acolhidas pelos programas (o que se denomina cobertura), quanto se os programas respondem ao que se considera socialmente serem necessidades das crianças. Necessidades de "guarda" da ótica dos pais/mães e de acolhimento da ótica das crianças podem não coincidir. E é necessário estar-se alerta para conflitos de interesse nesse campo: por exemplo, a jornada de trabalho dos pais/mães pode ser muito extensa para a necessidade de acolhimento da criança.

Algumas crianças têm também necessidades especiais (por exemplo, suplementação alimentar quando diagnosticam-se carências nutricionais) e outras têm necessidade de proteção (por exemplo, em caso de maustratos). Para avaliar se estas necessidades estão sendo respondidas qualitativa e quantitativamente, os indicadores a serem selecionados serão de outra natureza.

Os(as) trabalhadores(as) em educação infantil têm necessidades de formação (prévia e continuada), de condições de trabalho, de salário e de status profissional.

Na América Latina pouca atenção vem sendo dada à avaliação das necessidades de "guarda" e dos profissionais. Além disso, confundem-se necessidades de proteção e necessidades especiais com necessidade de acolhimento. Finalmente, confundem-se necessidades dos pais/mães com as das crianças: poucos dados são dispo- 
níveis chegando à unidade de análise criança, como recomendam textos recentes (Qvortrup, 1994), contentando-se com outras unidades, tais como domicílio, família ou pais (e/ou mães). Por exemplo, investigar quantas mães que trabalham fora têm filhos com menos de 7 anos oferece um tipo de retrato diferente daquele que responderia à pergunta: quantas crianças com menos de 7 anos são filhos(as) de mulheres (mães ou substitutas) que trabalham fora? Ou ainda: afirmar que tantas mulheres têm apenas uma criança com menos de 7 anos são filhos(as) únicos(as), e assim poder-se avaliar quantas crianças teriam necessidade a ser suprida de interação com coetâneos.

A demanda é uma necessidade sentida e expressa. Ela pode ser explícita ou latente: a explícita é avaliada através da procura de um serviço. A demanda latente é aquela que não se expressa espontaneamente, por alguma razão (distância entre domicílio e equipamento, qualidade ou tipo de serviço oferecido etc). A única forma de aferição da demanda latente é a realização de enquetes específicas. No Brasil são raríssimos, quase inexistentes, os estudos sobre demanda: não sabemos quais as modalidades de serviços preferidos pela população e qual a extensão da demanda latente. Não dispomos de instrumentos para avaliar qualquer tipo de demanda, além da extensão da "lista de espera".

Além disto, confunde-se, freqüentemente, necessidade com demanda: considera-se que, desde que sejam pobres, todas as famílias de crianças pequenas têm demanda por serviços, olvidando-se da mediação de valores para que uma necessidade se configure em demanda (Bloch \& Buisson, 1998). Também, não se avaliam as demandas dos(as) profissionais quanto às condições de trabalho.

Finalmente, o provimento dos serviços, categoria que tanto pode ser descrita como a capacidade, isto é número de vagas disponíveis, quanto como o uso efetivo no caso das crianças. Por exemplo, no caso dos(as) profissionais, o provimento de suas necessidades e demandas pode ser entendido como a disponibilidade de estratégias para formação inicial e em serviço (cursos/vagas, supervisão) ou a existência de associações profissionais.

A pergunta chave passa a ser: o provimento responde a que tipo de necessidade e de demanda e de quem: há provimento compatível com o horário de trabalho dos pais/mães? Quantas são as vagas que respondem às necessidades de acolhimento socialmente consensuadas, isto é, vagas que respondam aos critérios de qualidade do serviço? Neste sentido, as taxas brutas de cobertura (indicador geralmente usado para avaliar a extensão do atendimento) são insuficientes para avaliar o provimento, devendo, portanto, ser qualificadas (Rosemberg, 1999).

Percebe-se que um modelo de avaliação que leve em consideração os três participantes (pais/mães, profissionais e crianças) e as três categorias (necessidade, demanda e provimento), complexifica as avaliações de custo-benefício: se pretendo ampliar a cobertura respondendo a necessidades de proteção das crianças a um custo mínimo, poderei estar eliminando de meu programa as necessidades de acolhimento das crianças, de "guarda" dos pais/mães e laborais dos profissionais.

Tal modelo permite que se explicitem opções para os atores sociais: por exemplo, quem arca com os custos (monetários ou não) e quem se beneficia com o provimento. Neste caso, a pesquisa estará, sim, desempenhando sua função pública: instrumentalizar os atores sociais para que negociem as prioridades (que são necessidades) com o máximo de conhecimento disponível.

FÚLVIA ROSEMBERG, doutora em Psicologia, é pesquisadora da Fundação Carlos Chagas e professora de Psicologia Social da PUC-SP. Suas principais pesquisas focalizam políticas públicas para a infância, especialmente na educação infantil. Nessa área, seus principais livros foram publicados em co-autoria com Maria Malta Campos, como Creches e Pré-Escolas no Brasil (que contou com a colaboração de Isabel M. Ferreira) e Creches e Pré-Escolas no Hemisfério Norte. E-mail: frosemberg@fcc.org.br

\section{ReferênciasBibliográficas}

ABRANCHES, Sérgio, (1987). Política social e combate à pobreza. Rio de Janeiro: Zahar.

ARRIAGADA, Irma, (1999). Límites económicos, sociales y políticos a la participación de las mujeres en América Latina. In: DAWN/ REPEN (org.). Reestruturación política y transformación social. La Paz: DAWN/REPEN, p. 43-54. 
BLOCH, Françoise, BUISSON, Monique, (1998). La garde des enfants: une histoire de femmes. Paris : L'Harmattan.

BARNETT, W. Steven, (1994). Costs and financing of early child development programs. In: YOUNG, M. E. (ed.). Early child development: investing in our children's future. Amsterdam : Elsevier Science B. V., p. 297-322.

CAMPOS, Maria M., (1997). Educação infantil: o debate e a pesquisa. Cadernos de Pesquisa, n. 101, p. 113-27.

CORAGGIO, José L., (1996). Propostas do Banco Mundial para a educação: sentido oculto ou problemas de compreensão. In: TOMMASI, L., WARDE, M. e HADDAD, S. (orgs.). O Banco Mundial e as políticas educacionais. São Paulo : Cortez/PUC/ Ação Educativa, p. 75-124.

EUROPEAN Commission, (1994). Monitoring childcare services for children. Bruxelles : European Commission.

GUIACHOUA, André, GOUSSAULT, Yves, (1993). Sciences sociales et dévélopment. Paris : Armand Collin.

IZQUIERDO, Maria J., (1994). Uso y abuso del concepto de género. In: ICD (org.). Pensar las diferencias, p. 31-53.

LAUGLO, John, (1997). Críticas às prioridades e estratégias do Banco Mundial para a educação. Cadernos de Pesquisa, n. 100, p.11-36.

MELO, Marcus A. B. C. de, COSTA, Nilson R, (1996). A difusão das reformas neoliberais: análise estratégica, atores e agendas internacionais. In: REIS E. et al. (org.) Pluralismo, espaço social e pesquisa. São Paulo : ANPOCS/Editora Hucitec, p.153-176.

MYERS, Robert, (1992). The twelve who survive. London/N. York : Routledge.

OZLAK, Oscar, O’DONNELL, Guillermo, (1976). Estado y políticas estatales en América Latina: hacia estrategias de investigación. Buenos Aires : BACERIS/G.E.CLACSO, n 4 , mar.
QVORTRUP, Jens, (1994). Childhood matters: an introduction. In: QVORTRUP, J. et al. (eds.). Childhood matters: social theory, practice and politics. Aldershot (England) : Avebury, p. 1-24.

ROSEMBERG, Fúlvia, (1989). A educação da criança pequena, a produção de conhecimento e a universidade. Cadernos ANPEd, n. 1 , p. 57-64.

ROSEMBERG, Fúlvia, (1999). O estado dos dados para avaliar políticas de educação infantil. Avaliação Educacional, nº 20, p. 5-58.

ROSEMBERG, Fúlvia, (2000). Uma introdução ao estudo das organizações multilaterais no campo educacional. In: KRAWCZYK, N., CAMPOS, M. M. e HADDAD, S. (org.) O cenário educacional latino-americano no limiar do século XXI. Campinas : Editora Autores Associados, p. 63-94.

SANTOS, Wanderley G., (1987). A trágica condição da política social. In: ABRANCHES, S. et al. (org.). Política social e combate à pobreza. Rio de Janeiro : Zahar, p. 33-64.

SPODEK, Bernard, (1982). Handbook of research in early childhood education. New York : The Free Press.

THOMPSON, John B.,(1995). Ideologia e cultura moderna: teoria social crítica na era dos meios de comunicação de massa. Petrópolis: Vozes.

TORRES, Rosa Maria, (1996). Melhorar a qualidade da educação básica? As estratégias do Banco Mundial. In: DE TOMMASI, L., WARDE, M. e HADDAD, S., (orgs.). O Banco Mundial e as políticas educacionais. São Paulo: Cortez/PUCSP/Ação Educativa, p. 125-194.

WOLFF, Laurence et al., (1994). Improving the quality of primary education in Latin America and the Caribbean. Washington : World Bank.

ZIMAN, John, (1979). Conhecimento público. São Paulo : Edição Itatiaia. 